\title{
A SUPERAÇÃO DA DISTINÇÃO ONTOLÓGICA ENTRE O HOMEM E A NATUREZA COMO DESAFIO ÉTICO NO ENFRENTAMENTO DA CRISE ECOLÓGICA GLOBAL
}

\author{
Maria Claudia da Silva Antunes De Souza ${ }^{1}$ \\ Josemar Sidnei Soares ${ }^{2}$
}

\begin{abstract}
Resumo: O presente artigo tem como objetivo demonstrar que a distinção ontológica entre o homem e a natureza presente na história do pensamento humano teve um papel determinante na eclosão da crise ecológica que atualmente ameaça o equilíbrio ambiental do nosso planeta. Após revisão histórica e conceitual das origens dessa distinção, especialmente nas tradições filosóficas e teológicas, apresentaremos os problemas que delas decorrem e tentaremos esboçar os contornos de novos princípios éticos possivelmente capazes de orientar o agir humano na direção de uma relação sustentável com o meio ambiente.

Palavras chaves PT-BR: Homem. Natureza. Crise ecológica. Ética. Ontologia.

\section{THE OVERCOMING OF THE ONTOLOGICAL DISTINCTION BETWEEN MAN AND NATURE AS AN ETHICAL CHALLENGE IN THE FIGHT AGAINST THE GLOBAL ECOLOGICAL CRISIS}

\begin{abstract}
The main goal of this paper is to demonstrate that the ontological distinction between man and nature present over the history of the human thought played a decisive role in the outbreak of the ecological crisis that currently threatens the balance of our planet' environment. After a historical and conceptual review of the origins of this distinction, especially in the philosophical and theological traditions, we will present the problems that arise from them and try to outline the contours of new ethical principles possibly capable of guiding human action towards a sustainable relationship with the environment.
\end{abstract}

\footnotetext{
${ }^{1}$ Doutora e Mestre em Derecho Ambiental y de la Sostenibilidad pela Universidade de Alicante - Espanha. Mestre em Ciência Jurídica pela Universidade do Vale do Itajaí - Brasil, Graduada em Direito pela Universidade do Vale do Itajaí - Brasil. Professora no Programa de Pós-Graduação Stricto Sensu em Ciência Jurídica, nos cursos de Doutorado e Mestrado em Direito e na Graduação no Curso de Direito da Universidade do Vale do Itajaí - UNIVALI. Coordenadora do Grupo de Pesquisa e Extensão Paidéia cadastrado no CNPq. Coordenadora do Grupo de Pesquisa - Estado, Direito Ambiental, Transnacionalidade e Sustentabilidade - cadastrado no CNPq/EDATS/UNIVALI

${ }^{2}$ Doutor em Filosofia pela Universidade Federal do Rio Grande do Sul (UFRGS). Mestre em Educação pela Universidade Federal de Santa Maria (UFSM) e em Ciência Jurídica pela Universidade do Vale do Itajaí (Univali). Especialista em Psicologia Social pela Universidade Estatal de São Petersburgo (Rússia). Possui livros publicados nas áreas de Desenvolvimento Empresarial, Filosofia, Educação e Direito. Mais de 20 anos de experiência na área empresarial, atuando na consultoria para instituições públicas e privadas. Professor no programa de pós-graduação stricto sensu em Ciência Jurídica da Univali. Itajaí - SC - Brasil. Professor na Antonio Meneghetti Faculdade e coordenador do laboratório 'Hard Cases'. E-mail: jsoares@univali.br. https://orcid.org/0000-0001-6412-4094Doutor em Filosofia pela Universidade Federal do Rio Grande do Sul (UFRGS). Mestre em Educação pela Universidade Federal de Santa Maria (UFSM) e em Ciência Jurídica pela Universidade do Vale do Itajaí (Univali). Especialista em Psicologia Social pela Universidade Estatal de São Petersburgo (Rússia). Possui livros publicados nas áreas de Desenvolvimento Empresarial, Filosofia, Educação e Direito. Mais de 20 anos de experiência na área empresarial, atuando na consultoria para instituições públicas e privadas. Professor no programa de pós-graduação stricto sensu em Ciência Jurídica da Univali. Itajaí - SC Brasil. Professor na Antonio Meneghetti Faculdade e coordenador do laboratório 'Hard Cases'. E-mail: jsoares@univali.br. https://orcid.org/0000-0001-6412-4094
} 
Keys words: Man. Nature. Ecological crisis. Ethics. Ontology.

\section{INTRODUÇÃO}

Recentemente, uma questão preocupante ganhou grande visibilidade nos meios de comunicação: a possibilidade de extinção das abelhas. Em um curto período de tempo, diversas matérias sobre o assunto foram publicadas em jornais, blogs, programas de televisão, canais digitais e outros veículos de informação ${ }^{3}$.

De tom alarmante, todas as peças advertem para o risco de extinção que esses pequenos insetos estão correndo e para o impacto que esse fenômeno poderia ter sobre nosso planeta - em particular, para os seres humanos. Segundo elas, o papel das abelhas no processo de polinização é tão decisivo que, caso deixem de existir, seria possível que nossa biosfera entrasse em colapso, levando também ao perecimento da humanidade.

Apesar de possuírem certa dose de sensacionalismo, essas matérias apresentam relatos de especialistas que reiteram enfaticamente a importância das abelhas para o equilíbrio natural da Terra. Em 2016, o Intergovernmental Science-Policy Platform on Biodiversity and Ecosystem Services (IPBES) publicou o "Relatório de avaliação sobre polinizadores, polinização e produção de alimentos", que traz uma análise aprofundada sobre os potenciais problemas que a diminuição ou desaparecimento desses animais poderia acarretar.

Ou seja, mesmo que as projeções mais trágicas possam ser exageradas à luz dos estudos científicos disponíveis, as consequências negativas da extinção dos polinizadores (entre os quais as abelhas são os mais importantes) são uma realidade que exige nossa atenção urgente.

No entanto, para além de nos advertir sobre um perigo iminente, essa discussão também traz à tona uma questão ainda mais profunda e que será um dos principais temas abordados neste trabalho: a íntima - mas frequentemente ignorada - relação existente entre o que poderíamos chamar de "mundo humano" e "mundo natural".

É comum, de maneira geral, tratarmos esses "dois mundos" como entidades dissociadas. Quando falamos sobre o mundo humano, geralmente nos referimos às nossas

\footnotetext{
3 Tais como "Como a extinção das abelhas coloca em risco o futuro da humanidade?...” (ECOA/UOL) ou “A extinção das abelhas poderia acabar com a vida na terra?” (Terra). Os links para acesso estarão listados nas referências.

${ }^{4}$ Tradução livre do título original: "The assessment report of the Intergovernmental Science-Policy Platform on Biodiversity and Ecosystem Services on pollinators, pollination and food production."
} 
sociedades, tanto no sentido daquele conjunto de convenções e instituições que estabelecemos para organizar nossa vida comunitária (a cultura, as leis, a economia, a política, a religião, etc) quanto no sentido dos espaços físicos que ocupamos com nossas cidades e demais obras de arquitetura humana.

Já quando falamos sobre a natureza - a fauna, a flora, os minerais, os rios, o clima e assim por diante - aparentamos sempre estar falando de outra coisa, não de algo em que estamos inseridos umbilicalmente enquanto organismos vivos. Tratamos o mundo natural como alheio e essencialmente diverso ao mundo humano, mesmo que capaz de afetá-lo de maneira decisiva (inclusive na forma de uma $\operatorname{ameaça~}^{5}$ ).

Essa distinção é tão forte em nossa cultura que parece possuir um caráter quase ontológico - é como se os humanos não pertencessem à natureza do mesmo modo que os demais seres o fazem. Uma das consequências mais imediatas dessa visão cindida da realidade fica logo evidente: as relações materiais e psicológicas que estabelecemos com algo que nos afeta serão muito diferentes daquelas que estabelecemos com algo do qual fazemos parte.

Certamente evitaríamos ao máximo agredir um todo que compomos, pois isso significaria uma agressão contra nós mesmos. Porém, provavelmente não teríamos (e, de fato, temos demonstrado não ter) o mesmo grau de hesitação diante do que meramente nos afeta, especialmente se entendermos que essa afecção é negativa.

Ao longo deste trabalho, tentaremos demonstrar como essa forma de encarar a relação homem-natureza se desenvolveu e influenciou nossas ações no decorrer da história, sendo determinante para os resultados que colhemos hoje em relação às questões ambientais, tanto como sociedade quanto como indivíduos.

Com esse objetivo, na seção seguinte, remontado à tradição filosófica e teológica, trataremos do que parece ser o fator originário da distinção entre o homem e os demais seres da natureza: a faculdade da razão.

Depois, abordaremos o papel da nossa racionalidade na criação do "mundo humano" como entidade separada do "mundo natural", através de um ímpeto de dominação movido pelo medo das implacáveis forças naturais.

$\mathrm{Na}$ quarta sessão, procuraremos entender como as questões tratadas anteriormente contribuíram para o desenvolvimento de uma cultura antropocêntrica - onde a natureza se

\footnotetext{
${ }^{5}$ A concepção da natureza como uma possível ameaça ao ser humano será tratada na Seção 4 deste artigo.
} 
constituía em uma preocupação apenas enquanto meio para realização dos fins humanos - e como isso culminou na crise ecológica que o mundo enfrenta atualmente.

Na penúltima seção, explicitaremos o caráter ontológico e ético do problema a ser enfrentado, fazendo contrapontos com os aspectos da tradição que sugerimos terem nos trazido até a situação atual e, assim, esboçando os contornos de novas concepções capazes de balizar uma relação sustentável da humanidade com o meio ambiente,

Por fim, nas considerações finais, revisaremos muito brevemente a discussão proposta ao longo deste artigo, com a finalidade de reforçar os objetivos e a relevância de sua realização.

\section{AS ORIGENS DA DISTINÇÃO HOMEM-NATUREZA}

Para entendermos essa percepção dicotômica entre o que é natural é o que é humano, precisamos primeiro buscar seu ponto originário. Na história do pensamento filosófico ocidental, a faculdade de raciocínio da qual somos dotados parece sempre ter sido considerada como o grande fator distintivo entre nossa espécie e o restante da natureza. O homem não é apenas um animal, mas é um animal racional.

Apesar de, modernamente, essa visão ser profundamente associada à corrente racionalista fundada por René Descartes ${ }^{6}$, sua origem é muito mais antiga e seu alcance é muito mais amplo. Tanto Platão ${ }^{7}$ quanto Aristóteles ${ }^{8}$, por exemplo, já afirmavam que as almas dos seres vivos eram divididas em partes distintas e que apenas os humanos eram detentores da parte racional. Segundo Matos (2011, p. 49),

Parece haver uma distinção, tradicionalmente aceita, entre os seres humanos e os outros animais, com base no critério da capacidade de conhecimento. Ninguém duvidaria de que há, de fato, uma enorme diferença entre o comportamento cognitivo do ser humano e o dos

\footnotetext{
${ }^{6}$ Segundo esse autor, "[a razão e o bom senso] é a única coisa que nos torna homens e nos distingue dos animais" (1987, p. 29)

${ }^{7}$ No livro A República (2017), Platão afirma que as almas possuem três partes: concupiscente, irascível e racional.

${ }^{8}$ Aristóteles discorre sobre as faculdades da alma na obra Sobre a Alma (2010), cujo título também já foi traduzido como Da Alma. São elas: nutritiva, perceptiva, desiderativa, de deslocação e discursiva (do entendimento).
} 
outros animais. Na teoria do conhecimento moderna, com efeito, uma concepção tradicional de razão é costumeiramente estabelecida como base desta distinção.

Mas, afinal, o que é isso que chamamos de razão? Max Horkheimer, em seu livro "Eclipse da Razão", faz uma provocação a esse respeito. Segundo ele, "quando se pede ao homem comum para explicar qual o significado do termo razão, sua reação é quase sempre de hesitação e embraço." (2002, p. 13).

De fato, os termos "razão" e "racionalidade" são tão presentes em nosso cotidiano que sua definição aparenta ser quase uma autoevidência - isto é, até sermos chamados a apresentá-la. Nesse caso, nenhuma descrição parece ser abrangente o suficiente para defini-la de maneira satisfatória.

Essa dificuldade enfrentada pelo "homem comum" não surpreende. Nem mesmo a Filosofia, que tem se ocupado de refletir acerca desse tema há mais de dois mil anos, foi capaz de chegar a qualquer consenso sobre ele.

Apesar dessa discussão ser de grande importância, não será possível abordá-la neste artigo, uma vez que transcenderia muito o escopo da reflexão proposta. De maneira geral, consideraremos a racionalidade como quela faculdade que permite ao ser humano fazer raciocínios complexos (tais como juízos, deduções, inferências, abstrações, etc), bem como produzir conhecimento e estabelecer consensos através de um sistema de linguagem arrojado.

O problema sobre o qual nos debruçaremos mais a fundo, no entanto, diz respeito à uma característica que parece comum à maioria dos conceitos formulados ao longo da tradição: que a razão confere ao homem não apenas uma distinção, mas uma posição de superioridade dentro do mundo natural.

John Locke (1987, p. 198), por exemplo, afirma que ela é "a faculdade pela qual o homem é suposto distinguir-se das bestas, e pela qual é evidente que ele as ultrapassa." No mesmo sentido, Leibiniz (1987, p. 389) a define como "uma faculdade, pela qual supomos que o homem se distingue do animal e o supera em muito".

Aqui, cabe nos perguntarmos: porque a racionalidade é considerada algo que nos distancia tanto dos demais seres e não apenas uma capacidade que possuímos, da mesma forma que os pássaros podem voar ou os peixes podem respirar dentro da água? 
Uma possível resposta para essa pergunta remonta à noção de "scala natura" também conhecida como "escada da natureza" ou "cadeia do Ser" - que nasceu junto com os esforços empreendidos pelos gregos antigos para compreenderem a natureza e o funcionamento de nosso mundo.

Esses pensadores concebiam o universo como uma um sistema ordenado, dotado de uma estrutura linear, onde cada componente teria seu lugar próprio acima ou abaixo dos demais. Sendo assim, eles classificavam os entes da natureza (desde os inanimados até os seres vivos) em uma ordem hierárquica de complexidade, sempre posicionando o ser humano no topo dessa hierarquia.

Com efeito, para Aristóteles (2006, p. 21), “a natureza nada fez de imperfeito, nem de inútil; ela fez tudo para nós [humanos].” Essa forma de compreensão da realidade influenciou profundamente todo o pensamento filosófico, científico e teológico subsequente.

Sem embargo, quase um século depois de Aristóteles, Crisipo vai afirmar que os cavalos e os bois existem apenas para trabalhar para o homem, da mesma forma que o porco existe para ser abatido e servido como alimento. Panécio de Rodes e Posidônio de Apaméia (Estoicismo Intermediário), Epicteto, Sêneca e Marco Aurélio (Estoicismo do Último Período), porém, vão introduzir estas idéias no mundo romano, e elas acabam por exercer uma grande influência nas ciências, na ética e no direito romano, de modo que os animais não tiveram uma melhor sorte sob o governo dos Césares. Com o declínio do Império Romano, porém, essa herança filosófica passa a ser da Igreja Católica, de modo que os seus principais representantes, Santo Agostinho e São Tomás de Aquino, a partir da teoria da grande cadeia da vida vão ressaltar que a capacidade de pensar é um atributo espiritual exclusivo do homem, e portanto, é a diferença fundamental entre ele e os demais seres animados. (SANTANA, 2006, p. 51)

Além da tradição filosófica, a tradição judaico-cristã também tem um papel determinante na consolidação dessa visão sobre a superioridade humana com relação ao restante da natureza. Afinal, conforme nos informa o livro do Genesis (1,27-30), nós somos as 
únicas criaturas feitas à imagem e semelhança de uma divindade onipotente, onipresente e onisciente.

Esse fato, por si só, já seria suficiente para nos colocar em uma categoria completamente apartada. Mas, além disso, todas as outras criaturas foram colocadas sob nosso domínio por essa mesa divindade, que orienta: "Sede fecundos, multiplicai-vos, enchei a terra e submetei-a; dominai sobre os peixes do mar, as aves do céu e todos os animais que rastejam sobre a terra."

Assim, seja por sua capacidade cognitiva superior, por sua posição na cadeia do ser ou pelos designíos de uma divindade, podemos afirmar que as concepções filosóficas e teológicas tradicionais ajudaram a consolidar a percepção de que o ser humano ocupa uma posição privilegiada no mundo, estando acima do restante da natureza. Mais do que isso, essas tradições também parecem nos autorizar a utilizá-la de acordo com nossa vontade, seja ela qual for.

\section{A DOMINAÇÃO DA NATUREZA E O SURGIMENTO DO "MUNDO HUMANO"}

De fato, ao longo da história, a razão serviu como ferramenta de dominação da natureza. Adorno e Horkheimer (1985) afirmam que tanto os rituais xamânicos e religiosos do passado quanto a impressionante ciência moderna são frutos desse mesmo propósito.

Antes, em seu estado primitivo, o sofrimento e a morte só se faziam realidade para o ser humano no momento em que este era por eles confrontado. Porém, com o desenvolvimento de nossa capacidade cognitiva, os indivíduos começaram a tomar consciência de sua finitude e do constante risco ao qual estavam expostos.

Nesse sentido, a força implacável dos fenômenos e das leis do mundo natural se constituíam em uma permanente ameaça. A natureza, da qual antes fazíamos parte de maneira absolutamente simbiótica, passa a ser vista como uma força antagônica à nossa existência.

Por esse motivo, através do uso de nossa racionalidade, buscamos entender, intervir e controlar os processos naturais, com o intuito de utilizá-los ou modifica-los de acordo com nossos interesses e vontades.

O mito queria relatar, denominar, dizer a origem, mas também expor, fixar, explicar. Com o registo e a colecção dos mitos, essa tendência reforçou-se. Muito cedo deixaram de ser um relato, para se tornarem 
uma doutrina. Todo ritual inclui uma representação dos acontecimentos bem como do processo a ser influenciado pela magia. Esse elemento teórico do ritual tornou-se autónomo nas primeiras epopeias dos povos. Os mitos, como os encontraram os poetas trágicos, já se encontram sob o signo daquela disciplina de poder que Bacon enaltece como o objetivo a se alcançar. (Ibid, p. 7)

Em outras palavras, para se livrar do medo constante da aniquilação, o homem precisou se investir na posição de senhor com relação ao mundo natural. Para isso, além de buscar formas de manipular a natureza - primeiro através da magia, depois através da técnica - ele também criou um "mundo" próprio, apartado tanto quanto possível daquele, que é justamente o que chamamos de civilização. Como aponta Hans Jonas (2006, p. 32), “a violação da natureza e a civilização do homem caminham de mãos dadas".

Mas, ainda segundo o mesmo autor, "antes de nossos tempos, as interferências do homem na natureza, tal como ele próprio as via, eram essencialmente superficiais e impotentes para prejudicar um equilíbrio firmemente assentado". Mesmo que o homem possa ser considerado um ser superior com relação aos demais indivíduos que a compõe, ele não é mais forte do que a natureza como um todo.

Ou seja, apesar de conseguir realizar grandes feitos com o uso de sua razão, as ações do homem possuíam um alcance limitado, pois "todas as liberdades que ele se permite com os habitantes da terra, do mar e do ar deixam inalterada a natureza abrangente desses domínios" (Ibid, p. 32).

Já no espaço que cria para si (a "cidade"”), ao contrário, a existência humana obedeceria às suas próprias leis e ordem internas, estando menos suscetível à inexorabilidade do mundo natural. De certa forma, podemos dizer que os humanos, através da sua capacidade racional, construíram um mundo à parte justamente para se refugiar da ameaça que a natureza representa à sua conservação.

Essa é a origem da distinção entre os "dois mundos" que tratamos na introdução. Dentro dessa perspectiva, é curioso pensar que, nos dias atuais, estamos enfrentando um

\footnotetext{
${ }^{9} \mathrm{O}$ autor Hans Jonas, que será citado ao longo deste artigo, denomina "cidade" todo o conjunto da obra humana, tanto em seus elementos físicos quanto abstratos, que o homem constrói para ser a "casa de sua existência humana", em contraposição à sua existência como ser natural. (2006, p. 32-34)
} 
problema quase completamente oposto. Agora somos nós que estamos afetando o mundo natural de tal maneira que passamos a representar uma ameaça à sua conservação.

Esse problema, entretanto, também é paradoxal e será tratado mais a fundo na sequência deste trabalho: na medida em que o nosso mundo "artificial" passa a afetar a natureza negativamente, ele volta se colocar sob o risco de sucumbir às implacáveis forças naturais.

\section{O PROBLEMA DO ANTROPOCENTRISMO CULTURAL}

Todavia, antes de adentrarmos nessa discussão, abordaremos outra questão decorrente do que já foi exposto até aqui. O ímpeto dominador do homem (motivado por sua necessidade de autopreservação), a criação das sociedades como um mundo à parte da natureza e a visão filosófico-teológica de que o ser humano possui uma posição de superioridade dentro da ordem do cosmo acabaram culminando no que chamamos de cultura antropocêntrica ${ }^{10}$.

[...] essa cidadela de sua própria criação, claramente distinta do resto das coisas e confinada aos seus cuidados, forma o domínio completo e único da responsabilidade humana. A natureza não era objeto da responsabilidade humana - ela cuidava de si mesma e, com a persuasão e a insistência necessárias, também tomava conta do homem: diante dela, eram úteis a inteligência e a inventividade, não a ética. (Ibid., p. 33-34)

Com o surgimento das civilizações, os homens se voltaram completamente para si mesmos e para aquilo que dizia respeito à ordem interna dessa nova organização. Assim, desenvolveram a Filosofia, a Arte, a ciência, a política, a economia e tudo mais que caracteriza nosso mundo humano. No entanto, esse desenvolvimento se deu tendo como referência apenas as nossas próprias necessidades, interesses e anseios.

\footnotetext{
${ }^{10}$ Apesar de ter sido essencialmente teocêntrica, a Idade Média também entra nessa lógica no sentido exposto na Seção 2 deste artigo. Apesar de haver um Deus transcendente e superior que se torna a referência central de nossa cultura, o ser humano continua tendo posição de superioridade e domínio dentro do mundo material/natural.
} 
Nesse contexto, de maneira geral, a preocupação com a o mundo natural tinha um caráter meramente instrumental, na medida em que a natureza era vista como um meio para a manutenção da nossa vida e da nossa sociedade. Conforme Souza e Granado (2016, p. 11) “certamente, a proteção do ambiente não fazia parte da tradicional cultura humana. Ao longo da história, o homem dominou a natureza sem se preocupar com a viabilidade de causar a escassez dos recursos naturais".

Um dos problemas inerentes à essa visão de mundo antropocêntrica é de natureza ética e diz respeito à questão dos direitos dos animais. Como vimos nas seções anteriores, ao afirmarem que os demais seres vivos seriam, de algum modo, inferiores a nós e existiriam com a finalidade de nos servir, as tradições filosófico-teológicas ofereceram uma base justificacional para a exploração do meio ambiente pelo homem.

Essa autorização moral para usarmos inclusive outros seres sencientes de acordo com nossa vontade - mesmo à custa da dor, sofrimento e morte dos mesmos - é, certamente, problemática. Ela suscita um amplo debate, que merece uma discussão muito mais profunda do que seremos capazes de fazer aqui. Por esse motivo, não abordaremos essa questão de maneira direta no presente artigo.

No momento, focaremos no problema paradoxal apresentado ao final da sessão anterior. Por muito tempo, a questão da preservação do meio ambiente não constituiu uma preocupação presente no pensamento humano.

Do final dos anos 1960 ao início dos anos 1970, anos trágicos para o meio ambiente, houve o nascimento de um novo cenário mundial, pelo que fez insurgir os primeiros passos a identificação do problema, causando um abrir de olhos que reagiu em favor da busca por conscientização, avaliação e remedição da crise ambiental descoberta. (Ibid., p. 11)

Como apontado anteriormente por Jonas, até um passado relativamente próximo, o impacto de nossas ações sobre o mundo natural era tão pequeno que não colocava em risco o seu equilíbrio. Foi principalmente a partir da Revolução Industrial, com o desenvolvimento acelerado da ciência e da tecnologia, que essa lógica deixou de ser verdadeira. 
Com os avanços da técnica, a extensão dos danos contra a natureza que somos capazes de causar aumentou exponencialmente. Episódios como a tragédia de Chernobyl e os efeitos ambientais devastadores das bombas atômicas são apenas alguns exemplos desse fato.

Além disso, a Modernidade e a Pós-Modernidade também trouxeram consigo outro fenômeno que contribuiu para o agravamento desse cenário: o consumismo de massa. Com as diversas mudanças culturais em marcha após o final da Idade Média, o antropocentrismo se radicalizou, acabando por se transformar em um individualismo que "atribui um valor extraordinário ao direito dos indivíduos de decidirem por si mesmos que bens e serviços desejam obter" (BARBOSA, 2004, p. 49).

Assim, em vez do gênero humano, é o próprio indivíduo que passa a ocupar a posição de centralidade em nosso pensamento e em nossas organizações sociais. E, como afirma Lipovetsky (2005, p. 3), nossas sociedades passam a operar pela lógica da sedução.

A sedução nada tem a ver com a representação falsa e a alienada das consciências; é ela que dirige o nosso mundo e o remodela de acordo com um processo sistemático de personalização cuja finalidade consiste essencialmente em multiplicar e diversificar a oferta, em oferecer mais para que você possa escolher melhor, em substituir a indução uniforme pela livre escolha, a homogeneidade pela pluralidade, a austeridade pela satisfação dos desejos. (Ibid., p. 3)

Esse crescente desejo de consumo dos indivíduos gera o aumento tanto da demanda quanto do descarte de produtos industriais. Por consequência, produzimos grandes passivos ambientais com os quais nem sempre possuímos formas adequadas de lidar - tais como o aumento do consumo de recursos escassos, quantidades imensas de lixo e rejeitos químicos oriundos de seus processos de produção.

Não é por acaso que, atualmente, estamos enfrentamos uma grave crise ecológica de escala global. Se antes erámos capazes de fazer pequenos arranhões nos domínios da natureza, agora somos capazes de feri-la mortalmente.

O rápido desenvolvimento experimentado pelas sociedades humanas nos confrontou com uma situação completamente nova, onde as concepções antropocêntricas que marcaram 
os períodos anteriores já não são mais capazes de fornecer respostas satisfatórias aos problemas emergentes.

Concebida para a felicidade humana, a submissão da natureza, na sobremedida de seu sucesso, que agora se estende à própria natureza do homem, conduziu ao maior desafio já posto ao ser humano pela sua própria ação. Tudo aí é novo, sem comparação com o que o precedeu, tanto no aspecto da modalidade quanto no da magnitude: nada se equivale no passado ao que o homem é capaz de fazer no presente e se verá impulsionado a seguir fazendo, no exercício irresistível desse seu poder. Toda sabedoria acumulada até então sobre o justo comportamento esteve talhada para aquela experiência. Nenhuma ética tradicional nos instrui, portanto, sobre as normas do "bem" e do "mal" às quais se devem submeter as modalidades inteiramente novas do poder e de suas criações possíveis. (JONAS, op. cit., p. 21)

Mesmo que as preocupações com o problema da sustentabilidade já tenham ganhado grande relevância em nossa sociedade, ainda há um longo caminho a percorrer para mudarmos os paradigmas de pensamento que causaram esse problema em primeiro lugar.

\section{CRISE ECOLÓGICA: UM DESAFIO ÉTICO E ONTOLÓGICO}

Considerando tudo o que já foi exposto até aqui, fica evidente que a humanidade está diante de um grande desafio de natureza ontológica e ética - ontológica porque está ligado à forma como compreendemos os entes que compõe este universo e ética porque também diz respeito àquele conjunto de princípios que orientam as ações humanas.

Portanto, se a raiz da crise ecológica que nos ameaça está nas concepções de mundo que tem determinado nosso agir, é necessário buscar novas concepções e princípios que possam balizar as relações que estabelecemos com o mundo natural, de modo que esta permaneça sustentável ao longo do tempo.

O primeiro e mais importante passo para isso certamente é a superação da visão fragmentária da realidade que foi extensamente discutida ao longo deste trabalho. Afinal, de 
fato, todos os elementos que compõe nosso universo estão essencialmente interligados. Como nos informa Capra (1996, p. 40),

[...] a física quântica mostra que não podemos decompor o mundo em unidades elementares que existem de maneira independente. Quando desviamos nossa atenção dos objetos macroscópicos para os átomos e as partículas subatômicas, a natureza não nos mostra blocos de construção isolados, mas, em vez disso, aparece como uma complexa teia de relações entre as várias partes de um todo unificado.

Assim, podemos afirmar que tudo o que existe é parte de uma unidade elementar, até aqueles objetos que estão mais distantes de nós. Sabemos que a vida na Terra não seria possível sem o Sol. Sabemos também que a força gravitacional exercida pela Lua determina o movimento das marés, o que influencia diretamente no clima do planeta.

$\mathrm{Na}$ ordem cósmica, não existem entidades que existam de maneira independente ou isolada. Tudo está em conexão com tudo, de uma forma ou de outra. Em última instância, mesmo que não se veja dessa maneira, o ser humano também é um animal cuja sobrevivência depende da saúde de um ecossistema no qual todos os elementos tem importância fundamental.

Como já vimos na introdução, mesmo aqueles indivíduos encastelados em grandes edifícios, no seio de movimentadas megalópoles, cercados pelas mais diversas tecnologias de ponta, precisam dos polinizadores se quiserem seguir existindo.

Esquecer ou ignorar esse fato pode vir a se tornar o erro fatal cometido por nossa espécie. Afinal, os problemas ambientais que estamos enfrentando não são resultados de processos naturais que ocorrem à revelia da nossa vontade ou controle. Pelo contrário, é a própria ação humana está desencadeando os processos que colocam em risco nossa sobrevivência na Terra.

Em outras palavras, nossa tentativa de dominar a natureza para nos preservarmos dentro de um mundo humano agora está produzindo o efeito oposto.

Atualmente alcançamos um nível tal de agressão que equivale a uma espécie de guerra total. Atacamos a Terra no solo, no subsolo, no ar, no mar, nas montanhas, nas florestas, nos reinos animal e vegetal, em 
todas as partes, onde podemos arrancar dela algo para nosso benefício, sem qualquer sentido de retribuição e sem qualquer disposição de darlhe repouso e tempo para se regenerar. Mas não nos iludamos. Nós, seres humanos, não temos qualquer chance de ganhar esta guerra irracional e desapiedada, pois a Terra é ilimitadamente mais poderosa que nós. De mais a mais, nós precisamos dela para viver. Ela não precisa de nós. (BOFF, 2016)

É justamente o caso da possível extinção das abelhas, cujas causas diretas são o uso de pesticidas, a poluição e as formas como ocupamos e manejamos nossas terras (IPBES, 2016, XII). Se nada for feito para deter o que provocamos, provavelmente estaremos colocando em risco nossa segurança alimentar.

Que o destino de um ser tão pequeno (que costumamos tratar como irrelevante e inferior) possa influenciar tão decisivamente no destino da "poderosa" humanidade explicita claramente a indissociabilidade que existe entre o homem e a natureza.

Dentro dessa compreensão unitária do universo, àquela noção de hierarquia linear entre os seres que surgiu no pensamento antigo já não parece fazer sentido. Afinal, podemos continuar afirmando que as abelhas são inferiores, mesmo sabendo que a existência humana pode depender delas?

Mesmo que possamos utilizar diversos critérios de classificação para os mais diferentes propósitos (os estudos da Biologia, por exemplo), de uma perspectiva ontológica, essa ideia não parece se sustentar. A visão da ordem do cosmo como uma teia, conforme sugerido por Capra (1996), aparenta ser muito mais adequada.

Por fim, ainda nos resta discutir o papel que a razão deve exercer dentro dessa nova perspectiva ética. Afinal, como vimos na Seção 2, essa grande capacidade cognitiva da qual somos dotados sempre foi vista como o fator determinante para fundamentar as visões que nos colocam, de alguma forma, como seres alheios ao restante da natureza.

Quando escreveram "A Dialética do Esclarecimento", Adorno e Horkheimer se propuseram a "descobrir por que a humanidade, em vez de entrar em um estado verdadeiramente humano, está se afundando em uma nova espécie de barbárie” (1985, p. 2). No caso específico dessa obra, o objetivo dos autores era entender como a nossa razão 
supostamente esclarecida acabou gerando episódios tão bárbaros quanto os regimes totalitários que marcaram aquela época.

Contemporaneamente, certamente poderíamos fazer uma indagação parecida a respeito da questão ambiental: como o ser humano, dotado de uma inteligência elevada e capaz dos feitos mais incríveis, foi capaz de cometer violências tão brutais contra a natureza que acabaram provocando uma crise ambiental de tamanhas proporções?

Uma possível resposta à essa pergunta é dada por Milaré (2011, p. 114) ao afirmar que:

[...] o racionalismo moderno e o desvendamento dos segredos da natureza ensejaram ao homem a posição de arrogância e de ambição desmedidas que caracterizam o mundo ocidental contemporâneo. E o desenvolvimento científico-tecnológico, submetido ao controle do capital para efeitos de produção e criação de riquezas artificiais, desembocou nessa lamentável 'coisificação' da natureza e dos seus encantos.

É inegável que a racionalidade é uma faculdade fantástica. O problema, no entanto, está na instrumentalização que ela sofreu. Se usada como ferramenta criativa, a razão possibilita ao ser humano produzir desde as coisas mais básicas de seu cotidiano prático até as coisas mais belas e abstratas, como a Filosofia e a Arte. Mas, se usada para fins destrutivos, ela também será capaz de produzir as maiores atrocidades.

Infelizmente, ao longo da história e de forma ainda mais grave a partir da Modernidade, nossa capacidade cognitiva elevada foi predominantemente utilizada como artifício para dominar e subjugar a natureza, com a intenção de fazê-la servir aos propósitos humanos e sem qualquer consideração acerca das implicações disso para a sua sanidade. As consequências nós já conhecemos.

Por isso, se quisermos estabelecer uma relação positiva com a natureza, partindo da compreensão de que também somos parte dela, precisamos compreender esse grande poder que possuímos como uma espécie de compromisso de responsabilidade com o desenvolvimento mútuo - nosso e do planeta. 
Cada homem que nasce e vive neste planeta deve ter a responsabilidade de custodiá-lo e evolui-lo, no âmbito da sua casa, da sua horta, das suas roupas, do encontro com qualquer pessoa. Conseguindo compreender essa visão, surge imediatamente um encontro afável e cordial para qualquer um, seja humano, planta, alma vivente. É um encontro inteligente no qual existem hierarquias, não de poder ou de predominância, mas de prioridade de serviço. $\mathrm{Na}$ verdade, a ter a liderança do planeta devem ser aqueles que melhor sabem servi-lo e mantê-lo, desenvolvendo a sua vitalidade. (MENEGHETTI, 2017, 24).

Dentro dessa perspectiva, na medida em que promovemos o bem estar da Terra, promovemos o bem estar do homem. Porém, é importante ressaltar que o contrário também é verdadeiro. Afinal, “o ambiente é uma extensão do organismo do homem e reflete a ordem e desordem de quem é responsável por zelar e regular-se pelas leis imanentes na própria natureza." (SOUZA \& SOARES, 2018, p. 313).

Neste sentido, o "mundo artificial" que criamos não separa o ser humano apenas da natureza "externa", mas também faz com que ele perca o contato com aquela parte interna de si que está umbilicalmente conectada com a ordem da natureza.

Estamos nesta atmosfera coligada, onde se reverifica a vitalidade da parte se inserida na vitalidade em homologação com o todo. Nesse modo de entender, para colher o quanto nós estamos entitativamente no universo da vida, é preciso partir do saber colher o sinal informático que há em cada um de nós como célula, como momento, come ponto no espaço energético de um espaço vital. (MENEGHETTI, 2017, p. 14)

Para que uma concepção ética voltada para a preservação ambiental seja capaz de produzir o resultado ao qual se destina, é indispensável que os homens busquem também um processo de autoconhecimento. Enquanto partes dessa unidade universal que citamos acima, nós já possuímos a lógica da vida dentro de nós - e a vida jamais destrói a si mesma. 
É importante ressaltar que isso não significa que precisamos fazer uma "inversão de valores" de ordem hierárquica, colocando o mundo natural "acima" de nossa existência enquanto indivíduos particulares. Isso já seria voltar àquela visão fragmentada que estamos tentando combater.

Ao contrário, na medida em que compreendemos que só podemos existir no mundo e nos realizarmos no mundo, percebemos que investir nele significa investir em nós; aperfeiçoálo significa nos aperfeiçoar; preservá-lo significa preservar a nós mesmos. E todos os contrários também são verdadeiros. "A terra é um enorme dom do ser e, quem não sabe amála significa que não sabe amar a si mesmo e, tanto menos, a própria dignidade" (Ibid., p. 96).

Assim, nossa principal tarefa para enfrentar os desafios ambientais atuais, no âmbito da ontologia e da ética, parece ser o resgate tanto a nossa conexão externa quanto da nossa conexão interna com o mundo enquanto unidade orgânica da qual somos parte constituinte e indissociável.

\section{CONSIDERAÇÕES FINAIS}

De tudo que foi discutido ao longo deste trabalho, podemos concluir que, se não "acordarmos" para nossa condição de interdependência existencial com o mundo, não haverá chance de sobrevivência à longo prazo para a humanidade.

O homem nasce, cresce, é nutrido pelo cordão umbilical deste planeta. Até o nosso rosto e os nossos olhos ficam coloridos pela reação química dos fótons da atmosfera. Inclusive as nossas formalizações, as fantasias, a consciência. Definimo-nos humanos enquanto derivamos do húmus, do sangue orvalhado desse imenso ventre que é a "mãe terra”: essa é nossa estação vital. (MENEGHETTI, 2011, p. 286-287)

Não importa quão longe nosso pensamento ou nossa técnica alcance, se ela fizer isso às custas da degradação do equilíbrio natural que nos sustenta, mesmos nossos empreendimentos mais grandiosos não passarão de um esforço em direção à autodestruição. De fato, a crise ambiental que enfrentamos atualmente já um sinal claro do destino trágico para o qual nossas ações estão nos levando. 
Porém, a via de saída para essa encalacrada em que nos colocamos não será pelo mesmo caminho que nos trouxe até aqui. As concepções de mundo que nos fizeram encarar a realidade de maneira dicotômica e nos "separaram" do restante da natureza precisam ser revisadas com o intuito de reestabelecer a sanidade do Planeta Terra e promover a sustentabilidade da nossa existência como parte dele. Esse foi o escopo da tarefa a qual nos propusemos aqui.

Além disso, outro ponto que procuramos demonstrar foi a influência fundamental que algumas correntes de pensamento desenvolvidas ao longo da história da humanidade exerceram sobre nosso modo de viver e pensar tanto o mundo quanto a nós mesmos.

Podemos afirmar que os trabalhos intelectuais desenvolvidos por esses pensadores foram determinantes para a construção da realidade que vivemos hoje, tanto em seus aspectos positivos quanto negativos. Apesar deste artigo ter se concentrado na questão ambiental, é notório que o mesmo se aplica à todas as esferas da vida humana.

A reiteração dessa influência pode parecer quase trivial, mas, na verdade, é muito importante para nos lembrar da importância e do impacto que nossas reflexões podem ter sobre o rumo das coisas. Além disso, essa lembrança também nos coloca em uma posição de responsabilidade perante à realidade: se o mundo está enfrentando uma crise, qual pode ser a nossa contribuição?

No escopo do Direito, Soares, Souza e Ferrer afirmam que (2020, p. 44),

Quando as opiniões emitidas pelos intelectuais jurídicos começam a ganhar corpo em meio à sociedade, passam a se manifestar também como consciência jurídica, como percepção de um grupo, parte ou todo da sociedade. O resultado do trabalho intelectual, então, quando visa mudança da realidade jurídico-política, precisa passar pela capacidade de influenciar a consciência jurídica.

Neste sentido, nossos dois principais objetivos com este artigo foram elucidar as possíveis origens históricas da crise ecológica que vivemos atualmente e, como contraponto, propor novas formas de encarar nossas relações com o meio ambiente, de modo a contribuir com a mudança de pensamento necessária para frear esse processo destrutivo. Afinal, "não se 
ajuda o humano com revoluções externas, mas com revoluções interiores."11 (MENEGHETTI, 2017, p. 231).

\section{REFERÊNCIAS}

A EXTINÇÃO das abelhas poderia acabar com a vida na terra? Terra, 2017. Disponível em: $<$ https://www.terra.com.br/noticias/climatempo/a-extincao-das-abelhas-poderia-acabar-coma-vida-na-terra,c0037cfc7c5dc4c4ee2b226c1ade956049xt58pl.html>. Acesso em: 14 de setembro de 2021.

ADORNO, T; HORKHEIMER, M. Dialética do Esclarecimento: fragmentos filosóficos. Trad.: Guido de Almeida. Rio de Janeiro: Jorge Zahar Ed., 1985.

ARISTÓTELES. A política. $3^{\mathrm{a}}$ ed. Trad.: Roberto Leal Ferreira. São Paulo: Martins Fontes, 2006.

Sobre a Alma. Trad.: Ana Maria Lóio. Lisboa: Imprensa Nacional-Casa da Moeda, 2010.

BARBOSA, L. Sociedade de consumo. Rio de Janeiro: Jorge Zahar Editor, 2004.

BOFF, L. Sustentabilidade: o que é - o que não é. 4ª ed. Petrópolis: Vozes, 2016.

CAPRA, F. A Teia da Vida: Uma Nova Compreensão Científica dos Sistemas Vivos. São Paulo: Cultrix, 1996

DESCARTES, R.. Discurso do método. São Paulo: Nova Cultural, 1987.

FLORESTTI, F. Como a extinção das abelhas coloca em risco o futuro da humanidade? ECOA/UOL, 2021. Disponível em: <https://www.uol.com.br/ecoa/ultimasnoticias/2021/04/13/como-a-extincao-das-abelhas-coloca-em-risco-o-futuro-dahumanidade.htm?> Acesso em: 14 de setembro de 2021.

HORKHEIMER, Max. Eclipse da Razão. Trad.: Sebastião Uchoa Leite. São Paulo, 2002.

IPBES. The assessment report of the Intergovernmental Science-Policy Platform on Biodiversity and Ecosystem Services on pollinators, pollination and food production. Bonn: Intergovernmental Science-Policy Platform on Biodiversity and Ecosystem Services, 2016.

\footnotetext{
${ }^{11}$ Tradução livre.
} 
JONAS, H. O princípio da responsabilidade: ensaio de uma ética para a civilização tecnológica. Trad.: Marijane Lisboa e Luiz Barros Montez. Rio de Janeiro: Contraponto e Ed. PUC-Rio, 2006.

LEIBNIZ, W. Novos ensaios sobre o entendimento humano. São Paulo: Nova Cultural, 1987.

LIPOVETSKY, G. A era do vazio: ensaios sobre o individualismo contemporâneo. Barueri: Manole, 2005.

LOCKE, J. Ensaio acerca do entendimento humano. São Paulo: Nova Cultural, 1987.

MATOS, J. C. M. A questão da razão como critério distintivo entre homem e animal. Filosofia Unisinos, São Leopoldo, v. 12, n. 1, p. 48-55, jan/abr 2011. Disponível em: $<$ http://revistas.unisinos.br/index.php/filosofia/article/view/1003/228>. Acesso em: $17 \mathrm{de}$ setembro de 2021.

MENEGHETTI, A. O projeto homem. $3^{a}$ ed. Trad. e rev.: Claudia Montenegro e Gabriela Rockenbach. Recanto do Maestro: Ontopsicológica Editora Universitária, 2011.

; Antonio Meneghetti sobre... Projeto Terra. Recanto do Maestro: Fundação Antônio Meneghetti, 2017.

MILARÉ, E. Direito do ambiente: doutrina, jurisprudência e glossário. $7^{a}$ ed. São Paulo: Revista dos Tribunais, 2011.

PLATÃO. A República. 15 a ed. Trad.: Maria Helena da Rocha Pereira. Lisboa: Fundação Calouste Gulbenkia, 2017.

SANTANA, H. J. Espírito animal e o fundamento moral do especismo. Revista Brasileira de Direito Animal, Salvador, v. 1, n. 1, p. 37-65, jan 2006. Disponível em: <https://periodicos.ufba.br/index.php/RBDA/article/view/10240>. Acesso em: 18 de setembro de 2021.

SOUZA, M. S. A.; SOARES, J. S. Sociedade de consumo e o consumismo: implicações existenciais na dimensão da sustentabilidade. Revista Direito e Desenvolvimento, João Pessoa, v. 9, n. 2, p. 303-318, ago/dez, 2018. Disponível em: $<$ https://periodicos.unipe.br/index.php/direitoedesenvolvimento/article/view/815>. Acesso em: 15 de setembro de 2021.

; SOARES, J. S; FERRER, G. R. Política jurídica, vida de consumo e pandemia: a responsabilidade do intelectual jurídico. Revista Jurídica, Curitiba, v. 5, n. 62, p. 538-565, 
dez 2020. Disponível em: $<$ http://revista.unicuritiba.edu.br/index.php/RevJur/article/view/4972/371373115>. Acesso em: 15 de setembro de 2021.

; SOARES, J. S; GRANADO; J. R. M. A Contextualização da Avaliação Ambiental Estratégica (AAE) no Brasil: a Experiência Brasileira com o Implemento do Processo de Pensamento Estratégico. Revista Direito Público, Porto Alegre, v. 12, n. 69, p. 9-33, mai/jun 2016. Disponível em: <https://www.portaldeperiodicos.idp.edu.br/direitopublico/article/view/2640>. Acesso em: 12 de setembro de 2021 